\title{
APROXIMACIONES A LA MÍSTICA
}

\author{
Marta González de Díaz \\ Yolanda Hernández Cortés \\ Claudia Moreno Gómez \\ María del Pilar Ramírez Pérez \\ David Valencia Villamizar' \\ Cesar Adolfo Ávila²
}

\section{Resumen}

Al considerar la experiencia mística como el descubrimiento de una anamnesis de nuevas dimensiones espirituales, este artículo pretende enunciar algunos problemas de interpretación tales como identidad y lenguaje, además de algunos otros que pretenden una indagación de sí mismo, allegando con ello una fructífera conceptualización sobre la infinita riqueza de la experiencia mística, que quizás concierna a la parte más esencial de la adquisición del conocimiento en Occidente.

\section{Palabras clave}

Mística, identidad, lenguaje, escritura, simbolismo, discurso, feminidad

\begin{abstract}
Considering the mystical experience as a mnemical discovery of new spiritual dimensions in the human indagation of himself, this article tries to set parameters of interpretation like identity, language, among others, as able to be fruitful in the conceptualization of the infinite richness of the mystical experience, that perhaps concerns to the self core of the acquisition of knowledge in the West.
\end{abstract}

\section{Key words}

Mysticism, identity, language, writing, symbolism, discourse, feminity

Equipo de docentes de la cátedra Catalina de Siena de la Universidad Santo Tomás, que hacen parte del grupo de investigación del mismo nombre registrado en Colciencias (2003). En la actualidad están desarrollando un proyecto de investigación financiado a través del Fondo de Investigaciones, Fodein, - Usta, sobre la mística cristiana, identidad y escritura femenina, del cual surge este avance de investigación. E-mail: cdesiena@correo.usta.edu.co.

2 Estudiante de Historia, Universidad Nacional de Colombia. Colaborador del equipo USTA. 


\section{Introducción}

Este primer artículo corresponde a una aproximación hecha por parte del grupo a reflexiones realizadas en torno a la mística, su relación con el lenguaje y la construcción de la identidad, que a su vez se constituye en avance del proyecto de investigación "La mística cristiana, identidad y escritura femenina observada a través de tres religiosas: Santa Catalina de Siena, Sor Juana Inés de la Cruz y la Madre Josefa del castillo".

En lo que hace referencia a la mística, en un primer momento se retoma la derivación del término, a saber, mystikós, palabra que viene del griego y que de igual forma tiene relación con múein, cuyo significado hace referencia a cerrar los ojos y cerrar la boca, de lo que " misterio" remite "a algo oculto" ${ }^{3}$. De igual forma, se le podría interpretar como percibir el carácter escondido, no comunicado, de la realidad, no accesible a la vista, de lo que puede hablarse. Velasco, propone que para que pueda entenderse y se le dé un significado es necesario recurrir al cristianismo, que debió ser influenciado por el neoplatonismo y por la doctrina platónica de la contemplación, en la cual es necesario que se dé una "renuncia a los sentidos, a las operaciones intelectuales, a todo lo sensible e inteligible"4.
A este respecto Boff ${ }^{5}$ reseña que las concepciones religiosas (de ahí la importancia del cristianismo) procuran descubrir en sí varias dimensiones del misterio de la vida y los niveles de profundidad de la indagación humana. Identifican los grandes sueños y visiones del mundo y de las relaciones humanas y sociales que pueblan el imaginario y que, de vez en cuando, enardecen los corazones. En ese contexto, cobra sentido hablar de espiritualidad y de Dios no como realidades pensadas en sí mismas, sino como referencia presente en los conflictos humanos, en las grandes decisiones, en los avances y retrocesos, en fin, en el drama humano.

Hablar por lo tanto de mística es asumir un lado Luminoso-Numinoso ${ }^{6}$, aquella dimensión que alimenta las energías vitales, más allá del principio de interés, de los fracasos y de los éxitos. La mística es un adjetivo de misterio, palabra que ha sido fruto de reflexión, pero que de igual forma se relaciona con términos como aura, curiosidad, fascinación que recurre a descubrir lo desconocido, no comunicado y por lo tanto relacionada con la experiencia religiosa en los ritos de iniciación.

En lo que hace referencia al lenguaje, este lo consideramos de gran importancia para el desarrollo del trabajo, toda vez que, es a través de él y haciendo uso de él

2 Velasco, Juan Martín. El fenómeno místico en la historia y la actualidad. Madrid: Trotta, 1999, pp. 19-20.

$4 \quad$ En este tópico el horizonte no parece ser tan obvio, lo que se denomina "renunciar a los sentidos» implica asignar en las prácticas de sí un papel central a lo percibido, objetivizar al volver contenido consciente la actividad sensorial que predominantemente es de carácter no evidente en la cotidianeidad: el goce de los sentidos está reservado de manera especial a aquellos que renuncian a esos sentidos. Sobre la vivencia cristiana del cuerpo, en especial las claves constituidas en el cristianismo primitivo, cf., además de los últimos trabajos de Michel Foucault, Brown: Meter. El cuerpo y la sociedad. Barcelona: Muchnik.

$5 \quad$ Boff, Leonardo y Betto, Frei. La mística y la espiritualidad. Madrid: Trotta, 1996.

$6 \quad$ Numinoso: "perteneciente o relativo al numen como manifestación de poderes religiosos o mágicos, Diccionario de la Lengua Española T. II, Madrid, 1992, p.1454, concepto introducido en el bagaje de las Ciencias Sociales por Rudulf Otto, en su clásica obra Das Heilige (Io sagrado); por su parte Rafael Llopis, en la introducción a Viajes al otro mundo, Ciclo de aventuras oníricas de Raldoph Carter, de H. P. Lovecraft, caracteriza tal experiencia de lo numinoso así: "Las estructuras neurológicas arquetipantes y las estructuras ideológicas arquetipadas Ihaciendo uso del vocabulario del psicoanálisis jungiano, se trataría de una aproximación a esa dimensión de lo "numinoso»] quedaron reprimidas a nivel individual. Se convirtieron en objeto de nostalgia. Su vago recuerdo se mitificó: ya no somos todopoderosos pero lo fuimos entonces [el instante de la experiencia mística], el milagro, la experiencia directa de lo numinoso ya no existen en la vida [asumida en la cotidiana reiteración de los automatismos de la sociedad de consumol, pero entonces existieron. Ya no tenemos acceso a planos místicos, ni a dimensiones paralelas, pero entonces lo tuvimos. Los corchetes son añadidos. Así mismo, afirma Octavio Paz: "La experiencia de lo sobrenatural es la experiencia de lo otro, (...) el terror sagrado es pavor indecible precisamente por ser experiencia de lo indecible. En su forma más pura y original la experiencia de la "otredad" es extrañeza, estupefacción, parálisis del ánimo: asombro. El misterio -esto es la "inaccesibilidad absoluta" - no es sino la expresión de la otredad, de esto Otro que se presenta por definición como algo ajeno o extraño a nosotros. Lo Otro es algo que no es como nosotros, un ser que es también el no-ser». El Arco y la Lira, México F.C.E., 1994, p. 129. 
que nos vemos inmersos en la reflexión. Podríamos decir que por medio de él, somos introducidos en el mundo, reconocidos, nombrados, y de él nos servimos para tratar de interpretarnos, modificarnos ${ }^{7}$, nombrar, etc.

El lenguaje va a tener su mayor concreción en la palabra y vamos por lo tanto a perseguirla para saber qué se esconde detrás de ella. Gaston Bachelard dice:

(...) "Las palabras tienen sexo como nosotros y como nosotros son miembros del Logos. Como nosotros buscan sus realización en un reino de verdad; sus rebeliones, sus nostalgias, sus afinidades, sus tendencias están como las nuestras imantadas por el arquetipo del Andrógino"s.
De Certeau hablará del "verbo"como palabra dominante y hegemónica durante buena parte de nuestra historia humana. Ahora bien, a partir de: " $Y$ el Verbo se hizo carne", la palabra central por antonomasia, "elverbo," pierde su reinado y las " palabras", las hasta aquí excluidas del discurso comienzan a visibilizar su importancia. Por lo tanto ellas, su juego de posibles dentro del lenguaje, han de constituir un elemento de reflexión vital.

Con respecto a la identidad, ésta podríamos abordarla desde dos aproximaciones. Una primera constituida por la mística femenina ${ }^{9}$. Dentro de este orden, se puede visualizar históricamente como escritos producidos por mujeres. Pero además, nos referimos a una experiencia de realización interior del conocimiento vinculado al

7 Acerca del proceso de modificación de sí mismo como rasogo central en el proceso histórico de elaboración de la subjetividad, puede leerse Foucault, Michel. La Hermenéutica del sujeto, México: F.C.E., 2001, pero ya en la introducción a la Historia de la Sexualidad, T. II, El uso de Ios placeres, México: Siglo XXI, 1993, el filósofo francés planteaba una investigación acerca de los modos a través de los cuales "Ios sujetos se constituyen a si mismos" al interior de regímenes de verdad específicos, pesquisando en particular un cierto modelo de espiritualidad, cuyo germen se halla en la transición operada en los primeros siglos de la era cristiana y que en términos generales persigue un acceso por parte del sujeto a la verdad pasando por una "transformación"radical de sí, el abandono de una forma de interpretarse para pasar a otra dimensión de la consciencia: "El aspecto de iluminación, el aspecto del cumplimiento, el momento de la transfiguración del sujeto por el "efecto de contragolpe» de la verdad que él conoce sobre símismo, y que estremece, atraviesa, transfigura su sen. Hermenéutica del sujeto. Op., Cit. p.37.

8 Bachelard, Gaston. La Poética de la ensoñación. México: F. C. E. Breviarios., 1982, p. 81-82. En 2.»El mito del Andrógino. Jean Libis sostiene: «(...) por la realidad de los géneros gramaticales la lengua está impregnada de una androginia fundamental que, sin embargo, el uso, y también a menudo los filólogos, no toman muy en serio. Olvidamos por rutina y por "exceso de sensatez", el sexo de las palabras, el modelo antropomórfico que habita el lenguaje». Madrid: Siruela, 2001, p.150. cf. nota 17.

$9 \quad$ Para aproximarnos a una definición de lo femenino más allá-acá de la diferencia entre géneros proponemos la idea del "devenir mujer", según Io plantean Deleuze y Guattari en Mil mesetas, Capitalismo y esquizofrenia, Valencia: Pre-textos, 1997: se trata de mirar con otros ojos la estructura social de género, por eso se habla de "mujer" en tanto minoría subyugada por los hábitos cognoscitivos que se dan por descontados, "mujer"como lo impensable -por hallarse en el margen del pensamiento que solo ve lo que está dispuesto a ver-, como con el devenir-niño la propuesta es des-dogmatizar esas "verdades" que establecen como modelo de comportamiento al hombre-adulto y desde allí organizan la "percepción" de los individuos.

Devenir-mujer es romper la dicotomía esencia-apariencia, donde la esencia corresponde a un plano de trascendencia o trasmundo fuera del alcance inmediato de los sentidos, la esencia sería la metafísica, el más allá perfecto como certeza en sentido absoluto, por toda la eternidad. Lo femenino en ese orden de ideas, sería lo aparente, lo engañoso con relación a una verdad oculta.

Muy por el contrario en el devenir-mujer desaparecen esas dualidades, ya que al asumir una mirada desde lo subalterno las acciones ya no tienen un soporte trascendente que las aprueba o las condena de acuerdo a un orden moral previo, inmodificable; sino que se encabalgan en una sucesión de apariencias sin fin racional alguno (el egoísmo unidireccional del capitalismo).

En síntesis se trata de metamorfosear la creencia (culturalmente fabricada y administrada por las instancias de control social) en una identidad "natural», un rostro (en tanto criterio de subjetivación) dado de una vez y para siempre (que debe ajustarse a los valores jerárquicos y por lo tanto masculinos que sirven para entender el mundo, darle sentido a las cosas) y unas máscaras que serían postizas, o un maquillaje que alteraría la "verdad intrínseca» de cada persona; transformar esa creencia a partir de una actitud de problematización frente a cualquier referente invariable. Porque devenir mujer es estar por fuera de la diferencia entre géneros, haciendo fluir esos condicionamientos que pasan por intachables. 
aspecto femenino del cosmos en general ${ }^{10}$ o de cada ser humano en particular. (partiendo de que en cada ser humano existen, tanto el aspecto femenino como el masculino).

Y una segunda instancia que, históricamente, se puede apreciar desde la presencia de rasgos propios de la feminidad dentro de la historia de la mística, esta estaría constituida por lo femenino en la mística. Dentro de este orden de ideas, nos referimos a una manifestación de un eterno femenino universal en la dialéctica creativa de los contrarios, que en última instancia se integran en la unidad esencial y trascendente del ser.

Ahora bien, vale la pena tener en cuenta que, dentro del orden simbólico de las culturas tradicionales, lo femenino ha sido vinculado a la receptividad y a la pasividad y lo masculino a la actividad, por lo tanto la reflexión habrá de tocar de alguna manera el análisis de estos aspectos para ver en qué medida pueden determinar situaciones dentro del ámbito de la mística.

\section{Esbozo de una historia de la mística}

Si bien es cierto que nuestro trabajo ha de girar en torno a la mística cristiana, no por ello podemos desconocer que lo que denominamos fenómeno místico es $y$ ha sido percibido desde otras experiencias a las que haremos referencia de una forma somera.

En un primer momento nos encontramos con una mística que podríamos llamar primitiva, y que se puede abordar desde lo que se denomina el chamanismo, término que se deriva de "chamán», cuya significación alude a vidente o profeta. Los estados de trance tienen aquí una importancia especial. En estos trances o éxtasis el vidente alcanza la esfera de lo sagrado, entrando en comunicación con ello; pudiendo hacer uso de facultades paranormales como la clarividencia, la predicción del futuro, incluso la bilocación y el don de curar. Acceder a estos niveles exige la guía de un chamán. Los ayunos, vigilias y soledad desempeñan un importante papel en la preparación del chamán para el éxtasis. En muchas ocasiones estas prácticas se llevan hasta el extremo de conseguir una desintegración de la personalidad, simbolizando, según $M$. Eliade, el retorno al caos primitivo del que ha surgido el mundo. "Este es el signo, según Eliade, de que el hombre profano está a punto de disolverse y de que va a nacer en él una nueva personalidad" 11 .

Mientras que las aspiraciones místicas de las religiones primitivas están imbuidas de magia, hinduismo y budismo descansan sobre cimientos más filosóficos y espirituales.

El hinduismo, con sus manifestaciones literarias: los Upanishadas, el Bhagavad-Gita y el Vedanta, plasman toda una literatura mística de carácter superior.

Los principios consignados en estos textos hablan de "Atman» y "Brahman", que es también "Espíritu", es poder misterioso en el que se conjugan estas dos fuerzas que gobiernan el ser. Esta visión, en la que se tien-

10 "Los taoistas asociaban esta actitud receptiva a la visión "femenina"de la vida. La denominaban el "espíritu de/ valle". Lao-Tsé observaba:

El espíritu del valle nunca muere.

Es la mujer, Madre primordial.

Su puerta es la raíz del cielo y la tierra.

Es como un velo que apenas se ve.

Úsalo, nunca fallará.

En el orioginal chino se alude a la "mujer" literalmente como el "misterioso femenino". Lo femenino no es, pues, un velo que oculta la naturaleza, sino un hilo que se teje en toda su tela, y que, si se comprende y se cuida cuidadosamente, se puede utilizar para lograr grandes cosas». Marshall, Peter, La piedra filosofal, un viaje en busca de los grandes secretos de la alquimia. Barcelona: Grijalbo, 2001, p. 41.

$1 \quad$ Eliade, Mircea. Iniciaciones místicas. Madrid: Taurus, 1990, p. 89 y ss. 
de a identificar lo exterior con lo interior, es muy distinta de la visión judeo-cristiana en la que Dios creador está estrictamente separado de la creación temporal, a la que gobierna con su providencia. Esta tendencia de carácter dualista occidental dista mucho de la visión oriental hinduista, en la que Atman, que es también Brahman, está en el centro de todas las cosas porque es el que llena la más íntima profundidad de todos los seres.

El místico oriental busca, pues, unirse y encontrar a ese Dios, fundirse en la presencia divina y por consiguiente librarse de los sufrimientos de este mundo. De aquí se deriva la doctrina de la metempsicosis.

Entre los siglos I y II a. de C. aparece el Bhagavad-Gita, "Cantar de Dios", llamado a ser el libro religioso de más influencia en la India, el cual habla de la posibilidad de llegar a Brahman, ser supremo, por medio de la acción y no únicamente, como lo proclamaban los Upanishadas, a través de un intelectualismo refinado.

En Gita, el discípulo está llamado a adquirir conciencia de sí mismo de tal forma que pueda llegar al "Nirvana", estado de perfecta tranquilidad, o sea el Brahman. Para llegar a Brahman por la devoción de Krishna, que es su más perfecta manifestación, es preciso la práctica del yoga (palabra sánscrita que significa unión).

Descendiendo del hinduismo, el budismo, éste tiene tendencias similares, sobre todo en una de ellas, el budismo Mahayana, que se anticipó a la concepción del Maya (velo que encubre la realidad) en el sentido de calificar de ilusorio nuestro mundo espacio-temporal. Para una de sus escuelas, la realidad última es el Vacío ${ }^{12}$, el Sunya, sobre el que no se puede afirmar nada, pero que se alcanza por la experiencia mística. Según otra escuela, la última realidad es la "taleidad", algo que está más allá y fuera de todo lo que podamos concebir, que no es ni existencia, ni no existencia, sino una realidad suprema. Esta suprema realidad es también el "Buda eterno", no el Buda histórico, sino la naturaleza búdica, el "dharmakaya", el absoluto, que trasciende todo pensamiento y percepción del hombre.

A quienes logran penetrar en la identidad de todas las cosas, porque todos son lo mismo, se les llama bodhisattvas, es decir, los que han alcanzado el nirvana pero voluntariamente han aplazado su entrada en él para ayudar a los demás hombres a alcanzar ese mismo fin. Esta manera de actuar conduce a una ética del amor, de desprendimiento de sí mismo y por tanto de supresión del yo, porque éste no existe. Para llegar a este estado se requiere de una continua ascética a través de la "óctuple vía", cuyos estadios son: la visión correcta, el pensamiento correcto, el recto hablar, la acción correcta, el vivir correcto, el esfuerzo correcto, la atención correcta y la concentración correcta. Los dos últimos estadios conducen a los estados de trance o raptos que culminan en un estado de perfecta serenidad, en la que el místico se hace indiferente al placer y al dolor.

Tanto el hinduismo como el budismo tienen la idea de una unidad esencial de todos los seres, la negación absoluta de toda separación entre ellos y, por lo tanto, la meta de la vía mística no es la unión con el Otro, en mayúscula, sino la inmersión en el UNO con la consiguiente pérdida de la identidad.

Abordando el platonismo, el cual ha desempeñado un papel importante en la conformación de las grandes religiones monoteístas: judaísmo, islamismo y cristianismo, nos encontramos, con un acento marcadamente místico. De la filosofía de Platón (427-347 a. C), su principal seguidor fue Plotino (205-270 d. C.), para quien el sistema de pensamiento está basado en la tríada, cuyos

12 En Las vírgenes energúmenas, Marta Cecilia Vélez alude a lo femenino como aquellas posibilidades negadas por el logocentrismo, de cuño patriarcal, se trataría de la "racionalidad" en tanto forma de pensamiento dominante; sobre esa hipótesis de trabajo, y a propósito de la idea del "Vacío": "la mitología fundacional de los koguis dice: La madre no era gente, ni nada, ni cosa alouna», Medellín: Universidad de Antioquia, 2004, p. 13. Por otra parte, Julia Kristeva, estudiando la mística cristiana en Jeanne Guyon, profundiza en esta dimensión de vacuidad, negatividad, «no-ser» propio de la experiencia mística, lo cual emparentaría muy de cerca las visiones del misticismo oriental con el occidental. México: Siğlo XXI, 2000, pp. 261-279. 
miembros ni son personas, ni son iguales entre sí. El Uno es el miembro superior, que se denomina y se presenta como el Bien, principio del Ser. El segundo miembro es el "Nous", palabra griega que significa inteligencia, espíritu, mente. Este "Nous" ha sido engendrado por el Uno quien a su vez engendra la "Psykhe", el alma del mundo. La "psykhe" ha sido de gran importancia para la teología mística, al ser capaz de alcanzar la contemplación, ella, a su vez, es eterna e incapaz de todo mal. Esta doctrina guarda semejanzas con el hinduismo, en el sentido de un total desapego de todos los seres materiales y de una inmersión en el propio yo.

Ahora bien, entre los siglos IX y XII de nuestra era se desarrolló en Persia la llamada mística sufí, movimiento, que en sus orígenes se encuentra muy cercano a las ideas cristianas acerca de la persona de Jesús.

Entre las fuentes que contribuyeron a la conformación de la doctrina islámica se destacan dos, el cristianismo y el gnosticismo. Asumiendo un molde islámico, es de anotar que muchos de los milagros y de las afirmaciones de los Evangelios, así como las leyendas con que las iglesias de Oriente habían rodeado la figura de Jesús, fueron transferidas a Mahoma. En el misticismo islámico, Jesús ocupaba un lugar junto a Mahoma (de importancia apenas inferior a la del mismo Profeta), esto lo podemos ver en un canto del místico Al Hallay donde se confunden en una síntesis armoniosa las imágenes cristianas y gnósticas.

En cuanto a los sufíes, estos proclaman, así como las otras tres religiones monoteístas, su continua insistencia en la Absoluta trascendencia de Dios, lo cual haría desaparecer cualquier posibilidad de unión entre Dios y el creyente. En la mística sufí, al igual que en la judía y la cristiana, el acento está situado en el "amor", a diferencia de lo que ocurre en la mística Hindú, en donde el amor sólo es posible entre personas (no pudiendo existir en aquellas concepciones que afirman que el yo es idéntico al tú).

A partir del judaísmo, nos hallamos con que los elementos místicos insisten en la absoluta trascendencia de Dios, encontrándose esta idea en los primeros libros del Antiguo Testamento.

En el Génesis se habla de que el hombre fue hecho a imagen de Dios, es decir, que en la naturaleza del hombre existe una esfera que expresa un encuentro entre Dios y el hombre. El simbolismo que manifiesta una pérdida de la relación con Dios, por el pecado, menciona igualmente que esta amistad será restablecida con la promesa de la llegada del Mesías. Pero aún antes de este advenimiento, Dios eligió a determinadas personas para gozar de una relación con él. Primero Abraham, el patriarca de Israel, a quien Dios se le manifestó prometiendo hacerlo líder de un gran pueblo. Luego vendría Jacob que, al igual que Abraham, recibió la renovación de la promesa. En el Éxodo se nos habla de Moisés, el gran legislador de Israel: "Yahvé hablaba a Moisés cara a cara, como habla un hombre a su amigo". En esta versión encontramos un Dios absolutamente trascendente, al que puede acceder el hombre gracias a que es Dios quien ha tomado la iniciativa de crear y de revelarse. Dios es el Creador y el hombre su criatura, $y$ ambos pueden establecer una mutua comunicación. La revelación total de la "Palabra divina" y del Espíritu Santo está reservada para el Nuevo Testamento, en el que se halla el fundamento de la mística cristiana; pero su revelación parcial ya se encuentra en el Antiguo Testamento. Esto va a servir para alimentar la posterior mística de los judíos.

Posteriormente nos encontramos con la mística de los Padres del desierto, distinguiéndose allí dos etapas, una primera dedicada a la "mística de la luz" $y$ una segunda dedicada a la "mística de la oscuridad".

En la Edad Media nos hallamos ante la aparición de los monjes que nutren la vida cristiana con su ejemplo. Este período medieval contó con la presencia de hombres y mujeres que, siguiendo las huellas de sus antepasados, acentuaron su vida religiosa en conventos y monasterios en un completo retiro de sacrificio y oración. Durante el siglo XIII la vida religiosa europea experimentó la presencia de las órdenes mendicantes, que recorrieron los caminos dando testimonio de sus 
creencias religiosas y ofreciendo un ejemplo de entrega total a sus convicciones místicas.

El siglo XIV ve la aparición de los tres dominicos alemanes más destacados en cuanto a sus experiencias místicas: el maestro Eckhart, Juan Tauler y Enrique Suso, así como, Catalina de Siena, mística italiana que constituye uno de los ejes principales del trabajo que estamos abordando.

\section{Juegos del lenguaje}

Encontramos en Michel de Certeau una afirmación muy concreta en cuanto al problema del lenguaje para los místicos, él lo vislumbra como una lucha, y ¿ esta lucha qué significaría?

Ella no sería más que el deseo de poder expresar a través de "algo" (lenguaje) que en determinado momento visualizamos como absolutamente rígido, lo que no lo sería o que por lo menos no debería serlo, es el tratar de poner en palabras "lo inefable" "lo no deci$b / e^{\prime \prime}$, es en cierta forma poner dentro de parámetros de concreción lo que se vislumbra como continua deconstrucción, en la medida en que cualquier palabra, por rica que sea, no sería capaz de contener lo que desea expresar.

Michel de Certeau va a hacer una lectura de la relación del místico con el lenguaje a través del tiempo, que por ser de gran relevancia, vamos a retomar como eje de reflexión.

En un primer momento nos habla del lenguaje como el "gran ausente", el cual posteriormente va a ser recuperado dentro de lo que podría llamarse "un lenguaje técnico" que permita asir de alguna manera ese silencio y a la vez expresar esa experiencia.

Ahora bien, ese lenguaje técnico va a estar representado por el latín, que se pretende la lengua apropiada para "el bien decir" y que poco a poco va quedando vaciada de contenido en la medida en que no hace parte del mundo de la vida, como si lo hacen las lenguas vernáculas.

Es así como, a guisa de ejemplo, nos encontramos con el maestro Eckhart, a quien vemos oscilando entre las dos lenguas. El 13 de febrero de 1327 predica y muestra un texto en latín acompañado por una explicación en alemán a favor de su fe. De hecho, su producción va a estar una parte en latín ("Las Qaestiones parisienses", "Opus tripartitum") y otra en su lengua materna, el alemán ("Los sermones", "Colaciones", "Los Tractates" y el "Libro de Benedicto"). Con las afirmaciones hechas nos podemos dar cuenta que existen ya unas limitaciones con el uso de la lengua culta, esas limitaciones precisamente han de estar allí donde el discurso es menos técnico y requiere por lo tanto dar cabida a expresiones más vivenciales.

El conflicto va a presentarse dentro de estos dos estadios que han creado una ruptura en el lenguaje mismo, uno por quedar preso de la inmovilidad y los otros por generar lo que llama de Certeau "fragmentos de una simbólica ${ }^{\prime 13}$, en donde se percibe la necesidad de la búsqueda de ese "gran ausente" que permita dar sentido. De Certeau dirá: "Naturalmente, la diseminación de la lengua referencial intensifica el retorno hacia una lengua original, que sirva a su vez de modelo a la producción $(. . .)^{\prime \prime 14}$.

En otro momento, la eclosión de producción mística bajo diferentes lenguas produce una gran dinámica al interior del lenguaje, toda vez que éste es menos particular en la medida en que entran en escena diferentes culturas, todas ellas pretendiendo dar cuenta de un mismo fenómeno, que a la vez se mantiene inasible, puesto que a la base de él se encuentra la búsqueda de lo no materializable, en última instancia se encuentra la necesidad de hallar "lo místico" como el lenguaje transversal.

13 De Certeau, Michel. La fábula mística. México: Editorial Universidad Iberoamericana, 1993, p. 143.

14 Ibíd., Naturellement, la dissémination de la langue référentielle intensifie le rapport vers une langue originaire, qui sert à son tour de modèle à la production ( Cf. La fable mystique. París: Gallimard, 1982, p. 161), p. 143. 
El afán, ahora, va a estar constituido por la búsqueda de una "manera de escribir correctamente", que va a hacer caso omiso de la lengua hablada y con ello olvido, de alguna manera, de la movilidad y dinámica del lenguaje. Nace la retórica con la necesidad de sistematización, pero junto al arte del "escribir" también existe un arte del "hablar", del cual no nos podemos olvidar. De Certeau dirá: (...) "elarte de hablar ("ars dictandi") - va a reducirse poco a poco en la gramática, reemplazado por un "arte de escribir" y, en el siglo XVII, subordinado a un "arte de pensar" que organiza una lógica de los enunciados y ya no una problemática de la enunciación dialógica. La mística está ligada al destino de esas artes $^{\prime 15}$.

Sor Juana Inés de la Cruz va a estar ubicada dentro de este tipo de contexto, es decir, mientras que por una parte va a ser una gran exponente de la utilización de un "arte de pensar", sin embargo, su dinámica metafórica nos lleva a recrear una gran fuerza de reconstrucción; si bien es cierto que la lógica va a estar cumpliendo "aparentemente" un gran papel, también es cierto que las palabras danzan en las estrofas encontrándonos con la sensación del uso de la conceptualización para poder "darse un respiro" dentro del continuo fluir de las palabras.

Veamos las estrofas siguientes:

$$
\begin{array}{r}
\text { Finjamos que soy feliz, } \\
\text { triste pensamiento, un rato; } \\
\text { quizá podréis persuadirme, } \\
\text { aunque yo se lo contrario: } \\
\text { que pues sólo en la aprehensión } \\
\text { dicen que estriban los daños, }
\end{array}
$$

\author{
si os imagináis dichoso \\ no seréis tan desdichado. \\ Sínvame el entendimiento \\ alguna vez de descanso, \\ y no siempre esté el ingenio \\ con el provecho encontrado ${ }^{16}$.
}

La mística va a requerir en un nuevo momento de una forma para poder expresarse, tratando de escapar a esa organización de un lenguaje referencial, recurriendo por ello a otras formas, para no quedar presa de una vigilancia gramatical que se convierta en camisa de fuerza al manifestarse. La mística, por lo tanto, estará siempre atenta a encontrar la parte más dinámica del lenguaje, el sustrato último que le permita su relación con ese "otro" entendido como un lenguaje fundante. "Las palabras y las cosas deletrean allí un lenguaje organizado por el advenimiento de una Palabra que debe oírse entre los ruidos del mundo, ese cuerpo de metáforas donde una tensión ejercitada en las sutilezas de la retórica sabe reconocer el paso fugaz y los ardides de una voz fundadora, la del único"17.

De la vigilancia sobre la gramática, pasamos al papel que cumplen dentro de la escritura las palabras, a su organización y a cuáles de ellas van a jugar un papel preponderante. De Certeau nos indica la relevancia del "verbo" como eje central y en torno al cual se subordinan los otros elementos, de cómo el pensamiento va a construirse como producto de dicha organización discursiva, encontrando la preponderancia de ese elemento como lo más natural, como lo "normal", como la constitución de un "arte de pensar". "Tenemos allí una visión ajena a la concepción dicotomista que hace de la lengua un espacio verbal organizado por unos actos de

$15 \quad$ Ibíd., p. 149

16 De la Cruz, Sor Juana. Obras Completas. México: F.C.E. $4^{\circ}$ reimpresión, 1995, p. 5.

17 De Certeau. Op. Cit., p. 149. “Les mots et les choses épellent un langage organisé par les advenues d' une Parole à entendre dans les bruits du monde, ce corps de métaphores où une écoute exercée aux subtilités de la rhétorique sait reconnaître les passages et les ruses d une voix fondatrice, celle de l'unique". p. 168. Nos permitimos señalar la distinción en el francés entre los siónificantes que desionnan al español "palabra»: mot (masculino y que hace referencia a un elemento escritural) y parole (femenino y que hace referencia a la oralidad), que constituye un juego de palabras sin duda conceptual, que usa De Certeau en su obra y que en el fragmento citado puede ser más que sugerente. 
pensamiento" $^{18}$. Aquí ha de retomar el discurso de los místicos, que dice han de construir más un lenguaje dentro del ámbito de la "discordid", antes que del acuerdo. Es decir, el lenguaje no puede y no debe dejarse atrapar por los discursos existentes.

Por último De Certeau nos va a plantear la aparición del método, con dos caras de una misma moneda, una de ellas una secuencia que nos permite recorrer un camino, producir resultados, ahorrar tiempo, pero otra, como el elemento que en sí mismo es portador de su destrucción desde la lectura mística, la cual, si bien lo puede utilizar, en determinado momento, por la dinámica que vive, lo puede convertir en algo secundario, no determinante dentro de su misma estructura de continua ruptura.

\section{Oscilaciones entre identidad y deconstrucción}

¿En qué medida y hasta dónde podría desde un discurso actual hablarse de identidad, con todas las connotaciones que ella implica?

En la vivencia mística podríamos encontrar que se dan unos elementos presentes en todas las personas que experimentan esas experiencias místicas, tales, como:

La inefabilidad. El sujeto que la experimenta -padece o goza- afirma que escapa a toda expresión, que no es posible dar cuenta adecuadamente de su contenido mediante palabras.

- Un carácter noético: las vivencias místicas, aunque parecen corresponder a diversas modalidades de sentimientos, comunican también estados de penetración en profundidades de "verdad" que describen el conocimiento de Dios, más allá de las facultades ordinarias del intelecto discursivo.

- La transitoriedad: en donde la experiencia dura sólo breves instantes.

- La pasividad: por la cual el místico siente como si su propia voluntad estuviese en suspensión y realmente a veces como si fuera asido y sujetado por un poder superior.

¿Pero el que esto se repita puede servirnos para de allí deducir una identidad? O quizás de lo que se trata más bien es de hacer caso omiso de ello y decir que es todo lo contrario de una "identidad, que el fenómeno no puede ser equiparado a sus características, y que tal vez ante lo que nos encontramos es ante la producción de "algo" que se convierte en totalmente nuevo, totalmente otro, que se reconstruye según espacio-tiempos, que es palabra "nueva", metáfora, que no se deja marcar dentro de parámetros. Máxime cuando nos encontramos ante situaciones muy concretas como la propuesta de la existencia de lo "andrógino espiritual", ante lo cual nos hallamos no frente a un dualismo femenino/masculino sino ante una experiencia de la llamada "feminidad"19 que podría ser vivida ya sea por un hom-

18 Ibíd., p. 153

19 La obra del filósofo francés Jacques Derrida («Espolones, los estilos de Nietzsche». Valencia: Pre-textos, 1997), se sitúa en el intento de poner en evidencia el carácter in-decidible de la epistemología propia de la racionalidad capitalista. Es decir, se trata de denunciar la arbitrariedad del sistema de oposiciones sobre el que se erige el pensamiento occidental. Al mostrar que las categorías a través de las cuales interpretamos los acontecimientos de la "realidad" no se cimientan en ninguna coherencia intrínseca, ninguna "verdad-en-s'", ningún piso gnoseológico inamovible, la obra logra denunciar la artificiosidad de todo el esquema. Cuestionamiento al "logos", a ese "sol" desdoblado en significantes tales como: "palabra", "razón", "relato", "tratado", e incluso "Padre" como horizonte hacia el que tienden todas las operaciones mentales de Ios sujetos. Lo que queda en entredicho, entonces, es la lógica de la práctica, la manera como las personas han interiorizado esa forma de entender el mundo, diseñando así su identidad (sexual, de género) de acuerdo a esos cánones culturalmente disponibles. Lo que se denominaría "Logocentrismo", ya que ése logos como discurso racionalista pretende ser la única forma de conocimiento posible, excluyendo, por ejemplo, el mito, como sistema menos perfecto y atrasado respecto a las directrices de la modernidad. Conceptos como capitalismo, modernidad, racionalidad, patriarcalismo, método científico, son agrupados como componentes de ese mismo tipo de pensamiento rotulado con el término "falogocéntrico", en clara alusión al carácter vertical y excluyente de sus premisas incontestables. El "falo"en tanto tótem, eje, axiología, columna que se establece como "Verdad omnisciente", así la supuesta superioridad de los valores asociados a lo masculino, a Diospadre como un conjunto de operaciones de estabilización del pensamiento en criterios de competitividad, productividad desmedida, agresividad socialmente administrada, firmeza como invariabilidad del carácter, seriedad, etc. 
bre o por una mujer agrupados bajo el nombre de "mujeres de luz"

"Mujeres de luz" es una expresión que en el contexto del sufismo hace referencia a la experiencia mística como "El acceso especial a la luz [que] se les da a los seres humanos y [donde] las distinciones de género no desempeñan ningún papel en la esencia de nuestra humanidad, la esencia que esta abierta a la luz' ${ }^{20}$.

Es así como en San Juan de la Cruz encontramos, en Cántico espiritual entre el alma y Cristo su esposo:

Esposa

¿Adónde le escondiste,

Amado y me dexaste con gemido?

Como el ciervo huiste,

Habiéndome herido;

Salí tras ti clamando, y ya eras ido.

Pastores, Ios que fuerdes Allá por las majadas al otero,

Si por ventura vierdes

Aquel que yo más quiero,

Decidle que adolezco, peno y muero,

Buscando mis amores

Iré por esos montes y riberas,

Ni cogeré las flores

Ni temeré las fieras,

Y pasaré los fuertes y fronteras,

¡Oh bosques y espesuras,

Plantados por la mano del Amado,

Oh prado de verduras,

De flores esmaltado,

decid si por vosotros ha pasado? ${ }^{21}$.
En este poema podemos detectar como la posición que asume el místico es de pasividad y receptividad elementos asociados a lo "femenino". El papel que desempeña es el de la esposa como representante de las características arriba mencionadas.

Entonces, ¿dónde podríamos centrar una identidad? ¿Desde dónde plantearla? Veamos algunos ejemplos: si es en una persona diríamos que el "yo" se constituye en identidad; si en una entidad orgánica soportada sobre lo biológico podríamos argüir que existe una identidad de lo masculino y una identidad de lo femenino; si en el discurso, podríamos decir que existen discursos masculinos, femeninos, discursos de poder, discursos de saber, etc. De todas maneras, si echamos un vistazo a todo ello nos damos cuenta que todo este tipo de opciones no constituyen más que una clasificación que lo único que consigue es sosegar en el hombre la "angustia" ante el no poder atrapar dentro del discurso elementos que escapan a ello.

Y la "angustia" siempre aparece ante la visión de algo que escapa a ser manipulado, dominado. Los parámetros, las organizaciones, las clasificaciones calman la angustia, pero, también calman el afán de búsqueda continua. No es gratuito por ello que nos encontremos con los místicos tomados en primera instancia como los "lo$\cos ^{\prime \prime}$, precisamente por escapar a la normatividad rígida que, pretende atraparlos, son los distintos, como diría De Certeau, por "no participar de la circulación del significante".

Los locos, los idiotas, es decir todos aquellos a quienes se les detecte falta de cordura, provocan con su presencia el deseo de distanciamiento. Los discursos provocan hilaridad, se diría que se estructuran en un bullir de la ciudad y que son inarmónicos. Pero tal como lo proclama el aforismo bien conocido " volverse loco para

20 Beneito, Pablo. Mujeres de luz. Madrid: Trotta, 2001. p. 271.

21 De la Cruz, San Juan. Cántico espiritual entre el alma y Cristo su Esposo. Las mil mejores poesías de la lengua castellana. Madrid: Ediciones Ibéricas, p. 113. 
Ilegara ser sabio", manifiesta la paradoja que encarna este dicho. El aforismo se precisa en sentido amplio en la figura del Quijote, claro representante del mundo imaginario en la literatura. La locura de este caballero es proverbial, sus aventuras caballerescas lo llevan a realizar experiencias fantásticas que antiguos personajes han sostenido con el mundo, a imitación de las cuales don Quijote se sostiene en él. Este mundo fantástico le permite al hidalgo de la Mancha vivir en un universo dual en el que la fantasía desborda la realidad y le permite trasformar el mundo frío, estable, seguro de las normas establecidas y de los hechos dados, en situaciones humanas, en experiencias subjetivas imprevisibles y oscilantes. Lo que en verdad ocurre cada vez que el sentido y la pasión invaden ese mundo ficticio.

La situación del místico, mutatis mutandis, podría ser comparable a la del loco, en el sentido en que su aparición se da en una sociedad que vive y se orienta con parámetros diferentes, y aquí se alude no sólo a sociedades de los primeros siglos del cristianismo sino también a sociedades más establecidas, siglos XVI y XVII en que el fenómeno místico tiene como condición un alejamiento, es decir, los discursos que hablan de este acontecimiento no forman parte de él. Pareciera que se puede incurrir en una contradicción, pero al decir de Michel de Certeau, "estos hombres excéntricos y desaliñados, objeto de burla y desprecio, cargan consigo un secreto y se ofrecen a la multitud en un intercambio de opiniones que no es fácil descubrir, puesto que en un lenguaje cifrado marcan los efectos de la alteración del sentido. Su singularidad radica en la ruptura de cánones. Ellos trazan en las instituciones simbólicas una alteridad ya conocida de la multitud y que ellas olvidan siempre"22.
Sin embargo el relacionar lo místico con el misterio se entenderá como una designación de profundidad de la cual se impregna cada individuo. Boff comentaba que el misterio no equivale a enigmas, ni constituye una realidad opuesta al conocimiento. No es el límite de la razón. Por lo tanto no se puede absolutizar el paradigma moderno "científico-experimental y técnico-". Existen diferentes formas de interpretar la realidad y en ella los símbolos, la reflexión religiosa y filosófica, tienen cabida.

Lo que es la realidad es mayor a la razón y a la voluntad. La persona es más que un sistema de comprensión, el órgano de captación de ese misterio es el corazón y lo que Pascal llamó "esprit de finesse", espíritu de fineza. Es una actitud de simpatía, una capacidad de sentir a los demás en situación concreta.

"La locura de la loca consiste en no (poder) participar de la circulación del significante; en no ser, en relación a la locura misma, mas que su "simulación"; un no tener del verbo más que la experiencia de una traición; en mirarse en el valor constituyente de la palabra; en rechazar que "sea hecho según tu palabra", esta mujer no sabría estar alli, en el lugar del discurso colectivo. Perdida en el otro "donde la persona no es», ella desaparece $^{23}$.

El discurso de la identidad va a ir tomando diferentes ropajes a través del tiempo. Desde poder llegar a la afirmación de que, aún cuando sea, algo es igual a sí mismo. "La noción de identidad surge en Occidente con Aristóteles y según él constituye una de las leyes universales del pensamiento. De acuerdo con este principio cualquier cosa es idéntica a símisma $(A=A)$. Esta noción fue en términos generales dominante hasta el

$22 \quad$ Michel de Certeau. Op. Cit, p. 54

23 Ibíd., p. 52 "(...) La folie de la folle consiste à ne pas (pouvoir) participer de la circulation du signifiant; à n 'être, par rapport à la folie même, que sa 'simulation'; à n 'avoir du verbe que l'expérience d'une trahison; à se garder de la valeur constituante de la parole; à récuser qu' »il en soit fait selon ta parole' Cette femme ne saurait être là -là où la place le discours communautaire. Perdue dans I'autre, où 'personne ne sait', elle disparaîts. De Certeau. op. Cit., p. 57. 
inicio de la modernidad, cuando Hegel mostró que no es posible hablar de identidad de algo sin simultáneamente incluir la diferencia de ese algo con otro algo (...)"24. Pero, a pesar de ese paso, en la búsqueda de "lo otro", es decir de la diferencia para acceder a la explicación de lo mismo, "lo mismo" queda situado como aislado, como totalidad. Como la "razón" que se encarna históricamente ${ }^{25}$.

Pero desde allí comienzan a vislumbrarse otros problemas que harán eclosión ante la afirmación por parte del psicoanálisis de que existe todo otro mundo inexplorado de nosotros mismos que no nos permite afianzarnos sobre la certeza de lo que somos, sino sobre la incertitud del no conocimiento de nosotros mismos. Además de afirmar que, somos todo menos totalidades, por el contrario. Y es esto lo que constituye un eje central a nuevas dinámicas; Lacan dirá: "Si fuéramos totales, cada uno sería total por su lado y no estaríamos aquí, juntos, tratando de organizarnos, como se dice. Es el sujeto, no en su totalidad sino en su abertura. (...)"26.

Es en todo ello en donde se encuentra el quid del asunto, en que hemos centrado todo bajo el manto del "conocimiento", del "logos" organizador que nos permite, aparentemente, dar cuenta de la llamada "realidad", pero que en gran medida se ha constituido en la camisa de fuerza que niega la posibilidad de "lo otro".

25 Es pertinente volver a involucrar la perspectiva arqueológico-genealógica de Michel Foucault, quien no cree en la validez a-histórica de la episteme moderna, por lo tanto el "hombre» y la dominación androcéntrica que implica no son datos indubitables sino construcciones conceptuales de un cierto orden de discurso (Cf. "Las palabras y las cosas». México: Siglo XXI, 2001). El «hombre», para citar un ejemplo muy pertinente en el contexto de la presente investigación, es un efecto del funcionamiento enunciativo de una cierta cantidad de criterios históricamente contingentes. Por lo tanto tal dispositivo de poder puede ser repensado, al no ser un referente absoluto, es posible reimaøinar la forma como los sujetos se confeccionan a sí mismos una identidad. El sujeto es una forma de la interioridad, un pliegue dentro del cual se instalan formas de lectura de sí mismo que lo fabrican como algo distinto del entorno del que, sin embargo, toma esos cánones hermenéuticos. Se trata de un proceso de individuación, de diferenciación, con un afuera asumido como extraño, ajeno, inabarcable. El afuera sería un magma de posibilidades no formalizado en regímenes de habla concretos (el "sujeto", el "yo" apenas sería una forma de hablarse a sí mismo, entenderse, una manera de contarse lo que le pasa, la persona es la sumatoria de las interpretaciones que a lo largo del tiempo hace de sí misma), allende el «archivo» que organiza a nivel epistemológico (el de las operaciones gnoseológicas más profundas), la textura de la experiencia, la consistencia de la realidad.

26 Lacan, Jacques. Seminario 2. Introducción del gran otro. 7a. Reimpresión. Buenos Aires: Paidós, 1997, p. 365. 


\section{Bibliografía}

Abello, Ignacio y otros (1988). "Identidad y diferencia". En: Cultura, teorías y gestión. Pasto: Universidad de Nariño.

Bachelard, Gaston (1982). La poética de la ensoñación. México: F.C.E.

Beneito, Pablo y otros (2001). Mujeres de luz. Madrid: Trotta.

Boff, Leonardo y Betto, Frei (1996). La mística y la espiritualidad. Madrid: Trotta.

De la Cruz, San Juan. "Canto espiritual entre el alma y Cristo su esposo". En: Las mil mejores poesías de la lengua castellana. Madrid: Ediciones Ibéricas.

De la Cruz, Sor Juana (1985). Obras completas. México: F.C.E.
Eliade, Mircea (1990). Iniciación mística. Madrid: Taurus.

Graeff, Hilda (1970). Historia de la mística. Barcelona: Herder.

Kristeva, Julia (2000). El genio femenino. Buenos Aires: Paidós.

Lacan, Jacques (1997). "Introducción del gran otro". En: Seminario 2. Argentina: Paidós.

Velasco, Juan Martín (1999). El fenómeno místico. Editorial Valladolid: Trotta.

Vélez, Marta Cecilia (2004). La mitología funcional de los koguis Medellín: Editorial Universidad de Antioquia. 